\title{
Hatching of the eggs of Eulimnadia colombiensis (Branchiopoda) at different temperatures and regime of light
}

\author{
Túlio Paiva Chaves and Erminda da Conceição Guerreiro Couto
}

Post-Graduate Program in Applied Zoology - UESC; Benthic Ecology Laboratory of the Universidade Estadual de Santa Cruz (UESC), Departamento de Ciências Biológicas, Rod. Jorge Amado, km 16, 45662-900, Ilhéus, Bahia, Brazil. E-mail: (TPC) bio_tulio@yahoo.com.br

\begin{abstract}
Clam shrimps are small crustaceans typical of temporary ponds. To survive in these highly variable and unpredictable environments, they produce resistant eggs. These settle on the bottom of pools where they remain dormant, forming a cyst bank. We investigated the effects of light and temperature, both of which break the dormancy of Eulimnadia colombiensis eggs. Dormancy was not broken below $25^{\circ} \mathrm{C}$, irrespective of the effect of light. Hatching was highest $\left(27.8 \%\right.$ of eggs) at $30^{\circ} \mathrm{C}$ in continuous light. Light also influenced the development of eggs, and some nauplii hatched spontaneously without drought stress. Methods are suggested for the cultivation of this species in tropical areas.
\end{abstract}

Key words: Clam shrimps, dormancy, egg production, environmental influence

\section{INTRODUCTION}

Members of the Class Branchiopoda are common in temporary pools. These environments usually occur in hot, semi-arid, flat regions (Rabet and Thiery, 1996; Demeter, 2005). The temporary nature, abiotic factors, as well as the duration of the pools directly influence the life cycle of these animals (Marcus and Weeks, 1997).

The genus Eulimnadia Packard, 1874 (Family Liminadiidae) found in these microhabitats includes 48 species (Rabet, 2010) and has androdioic sexual system. This reproductive pattern is characterized by the presence of males and hermaphrodites genetically different, but phenotypically similar, differing only by the presence clasper (Sassaman and Weeks, 1993; Weeks et al., 2009).

Survival of populations these genus in this variable environment, especially in the ephemeris, depends entirely on the production of resistant eggs, which are really cysts. The single-celled egg develops inside the adult and the embryo within its cyst (or egg-shell) is expelled of carapace. The embryo can remain dormant, awaiting favourable conditions, possibly for year one or more (Weeks et al., 2002). During this stage the embryos are able to resist long periods of drought and, when rehydrated under favourable conditions of light, temperature and oxygen availability (Brendonck, 1996). However, even if the environment is favorable present, the hatch does not happen immediately. Dormancy breaking happens only when internal factors are activated, a mechanism known as "diapause" (Brendonck, 1996). This mechanism, linked to the "bet-hedging" strategy (asynchrony in hatching eggs of the same litter), can greatly reduce the chances of local extinctions, if the environment be altered abruptly, without the organisms have time to respond to changes (Seger and Brockman, 1987; Cáceres and Tessier, 2003; King and Masel, 2007; Benvenuto et al., 2009).

Individual hermaphrodites of Eulimnadia can produce thousands of eggs (Weeks et al., 1997), but as not all eggs hatch in 
the same instant (Benvenuto et al., 2009) those, whose dormancy is not affected, accumulate in the sediment. The accumulation of these cysts, not hatched, and those of other species in the bottom sediment of water bodies form the socalled "cyst banks". These, in turn, can provide us with information ranging from the richness of species in ecosystems (Arnott et al., 1999; Melo and Froehlich, 2001; Vandekerkhove et al., 2005) to temporal and spatial aspects of community dynamics (Brendonck and De Meester, 2003).

Light and temperature are primary factors in the hatching of the cysts of numerous species of zooplankton (Hairston et al., 1990; Fryer, 1996; Gyllstrom and Hansson, 2004). Large temperature variations are expected in temporary pools and studies have shown that this is a fundamental variable in the process of breaking the dormancy of cysts of many zooplankton species (May, 1987; Schwartz and Hebert, 1987; Vandekerkhove et al., 2005).

Eulimnadia colombiensis was described by Roessler (1989), in temporary ponds around Villavicencio and San Juan de Arama (Meta, Colombia). The species is recorded for Venezuela (Pereira and Garcia, 2001), Brazil (Rabet et al., 2012) and India (Weeks et al., 2006). Unlike other species of the genus, little is known of its biology. Nonetheless, studies were not conducted on the factors that influence the hatching rate of the eggs of Eulimnadia colombiensi. Here we investigated the hatching rates under different conditions of temperature in the presence and absence of light.

\section{Material And Methods}

Eulimnadia colombiensis adults were randomly collected from one fish pond at CEPLAC (Comissão Executiva do Plano da Lavoura Cacaueira) near Itabuna, Bahia, Brazil (14046'51.51"S, 39013'29.11”W). They were taken to the laboratory and cultured in aquaria using low aeration (after Weeks et al., 1997) and exposed to ambient light and temperature. After the adults had died, the water was drained and filtered in a fine mesh sieve $(80 \mu \mathrm{m})$, which retained the deposited cysts. The latter were allowed to dry naturally in Petri dishes and stored in $7 \mathrm{~mL}$ glass flasks.

After 45 days, simulation of time of interval average as that the tank remain dry, fourty two samples were taken of 30 eggs each, randomly selected, totalling 1,260 eggs of different hermaphrodites. Each sample was placed in Petri dishes and $40 \mathrm{~mL}$ of purified water was added to each Petri dish, 24 hours afterward further $10 \mathrm{~mL}$ were added.

Each series with three samples $(=90$ eggs) was submitted to different combinations of temperature and light for 48 hours as suggested by Weeks et al. (1997). The thermal amplitude recorded for local water ponds varied between $21^{\circ}$ (could months) e $29^{\circ} \mathrm{C}$ (hot months) (Tejedo et al., 2012). However, the environment studied by these authors differs from our local collection by presenting a lower volume of water and constant shade conditions. Preliminary tests were conducted at $15^{\circ} \mathrm{C}$ e $20^{\circ} \mathrm{C}$ and no hatching was observed.

A total of 14 treatments were tested at seven temperatures $\left(25^{\circ}, 26^{\circ}, 27^{\circ}, 28^{\circ}, 29^{\circ}\right.$, $30^{\circ}$ and $35^{\circ} \mathrm{C}$ ) in an incubator in the presence or absence of light. The temperature of water of each sample was monitored and maintained the same during time proposed. After this were period removed from the incubator and, with the aid of a stereomicroscope, hatched nauplii were pipetted and counted.

Finality, "bi-factorial ANOVA" test of, a $95 \%$ significance level, was used to analyse the existence of significant differences between the number of hatchings at different temperatures, and in the absence and presence of light, for each replica. The a posteriori Tukey test was used to determine the significance of potential differences.

\section{Results}

Light strongly influenced the hatch of the nauplii. The highest hatching rates $(17.8 \%$ and $27.8 \%$ ) were obtained at $25^{\circ} \mathrm{C}$ and $30^{\circ} \mathrm{C}$, respectively, in the cultures under constant light. Under this light condition, the difference between hatching rates at intermediate 
Table 1. Summary of results of Bi-factorial ANOVA for temperature range in the presence and absence of light.

\begin{tabular}{|c|c|c|c|c|}
\hline Source of variation & $\mathrm{df}$ & Residue & Variance $\quad F$ & $\mathrm{P}$ \\
\hline Temperature $(\mathrm{T})$ & 6 & 56.667 & 9.1119 .225 & $<0,001$ \\
\hline Presence of light (L) & 1 & 113.357 & 113.357110 .721 & $<0,001$ \\
\hline TxL Interation & 6 & 69.143 & 11.52411 .256 & $<0,001$ \\
\hline Residual & 28 & 28.667 & 1,024 & \\
\hline Total & 41 & 267.833 & 6.533 & \\
\hline
\end{tabular}

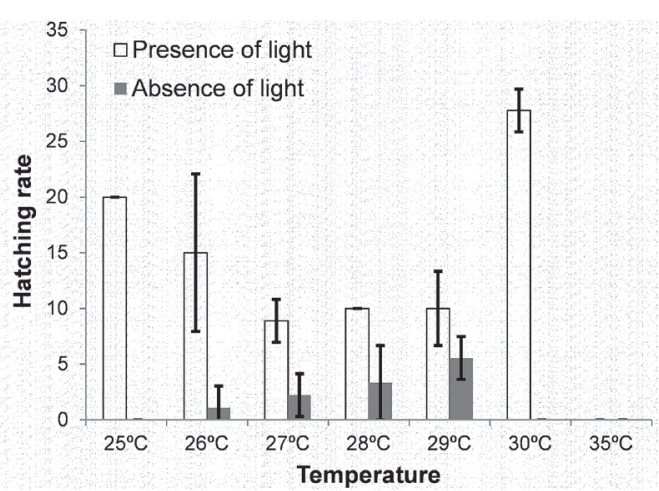

Figure 1. Hatching rate of nauplii of Eulimnadia colombiensis in the absence and presence of light, and at different temperatures.

temperatures $\left(26^{\circ} \mathrm{C}, 27^{\circ} \mathrm{C}, 28^{\circ} \mathrm{C}\right.$ and $29^{\circ} \mathrm{C}$ ) did not show a clear pattern. However, when eggs underwent these same temperatures in the absence of light, there was a gradual increase in hatching rate from $27^{\circ} \mathrm{C}$ to $29^{\circ} \mathrm{C}$ (Fig. 1). None of the eggs hatched at $35^{\circ} \mathrm{C}$ disrespected of the light regime.

The results showed that there is interaction between temperature and light on the hatching rates, the presence of light being fundamental in increasing the number of hatched nauplii (Tab. 1).

With respect to the different paired temperatures, the a posterior Tukey test showed significant differences between the samples in the presence of light of the pair $25^{\circ} \mathrm{C} \mathrm{X} 27^{\circ} \mathrm{C}$ and in all the combinations with $30^{\circ} \mathrm{C}$. In the absence of light no significant differences between pairs of temperatures were observed.

In addition to the above findings, we also observed that light positively affects the development of individuals after hatching. In the presence of light, the nauplii were shown to be active, free-natant and with no trace of egg connected to the body, contrary to what was observed in the absence of light. Dead nauplii were found among the set great of eggs where were extracted the samples for the study, suggesting the occurrence of hatching without water stress.

\section{DisCUSSION}

Both temperature and light regime are critical in the breaking of dormancy of Eulimnadia colombiensis cysts. The rates of hatching varied greatly as these environmental factors changed. The highest hatching rates were at $25^{\circ} \mathrm{C}$ and $30^{\circ} \mathrm{C}$ in the presence of constant light. However, at small temperature intervals $\left( \pm 1^{\circ} \mathrm{C}\right)$ and in absence of light, the gradual increase in the hatching rate strongly suggests that temperature is an important stimulus in breaking dormancy.

The temperature variation in local temporary ponds is very small (Tejedo et al., 2012), with daily values recorded between $21^{\circ} \mathrm{C}$ and $25^{\circ} \mathrm{C}$ (Tejedo, pers. comm.). However, our data show that hatching did not occur below $25^{\circ} \mathrm{C}$ after 48 hours of incubation in either the presence or absence of light so it may be necessary to extend the incubation period. It is likely that under natural conditions the hatching eggs need a period exceeding 48 hours. The situation is less clear at higher temperatures. None of the eggs hatched at $35^{\circ} \mathrm{C}$, which was unexpected in tropical species that living in areas where the temperature of the water exceeds these values into higher irradiation times. This result suggests that this species of the genus Eulimnadia, despite the large phenotypic plasticity (Rabet, 2010), the temperature variation can be an important factor in establishing the limits of their biogeographical distribution.

The light influences not only the number of cysts that will hatch but also the subsequent 
development of nauplii. Nauplii that hatched in the presence of light proved to be active and with no trace of residual egg. Cysts incubated in the dark remained a pre-nauplius, inactive and the residual of the egg remained connected to the body, suggesting that light plays an important role in the species development.

For populations of E. colombiensis from tropical regions with high rainfall, we suggest that cultures should be made at $30^{\circ} \mathrm{C}$, under constant presence of cold light. This value is higher than suggested by previous authors (Weeks et al., 1997, 1999, 2001; Rogers et al., 2010) for other species of the same genus. However, the consulted works dealt with populations of species from regions with different climatic characteristics. Thus, information about the place of origin of the specimens is key to the guidelines of an efficient cultivation for scientific reasons.

When comparing the egg production between $E$. colombiensis and E. texana, the difference is apparent. The average initial egg production by E. colombiensis, originating from the same area of study in question is 345 eggs.ind-1.d-1 (Chaves, 2014). Much higher than its congener E. texana, studied by Weeks et al. (1997), in which the initial production was -50 eggs.ind-1.d-1. When we compare the contribution to the bank of eggs between coexisting genres, other observations arise. In one experiment (Chaves - unpublished data), comparing as absolute number of eggs of the coexistents Eulimnadia (Conchostraca) and Dendrocephalus Daday 1908 (Anostraca), in $100 \mathrm{~g}$ of dry sediment from small puddles ( $\left.1 \mathrm{~m}^{2}\right)$ and large $\left(-400 \mathrm{~m}^{2}\right)$, it was observed that smaller pools have a greater number of Eulimnadia eggs while larger pools have a higher number of Dendrocephalus. This difference in colonizing potential can be reinforced by the difference in the life cycles of the two genera (Eulimnadia 16 days, personal observation, and Dendrocephalus - 15-75 days, see Lopes et al., 2011; Rabet and Thiery, 1996; Pereira and Gonzalez, 1994). Thus, individuals of Eulimnadia reach adulthood and reproduce faster, increasing its power to colonize ephemeral environments. Thus, in case of competition between these groups, E. colombiensis has an advantage in the initial colonization. Further studies are needed to test this hypothesis.

Just as in the natural environment, the variations found between hatching plates subjected to the same conditions, and the existence of percentages of hatching without a clear pattern, may be explained by the socalled bet-hedging mechanism. This strategy can be understood as a moment of hatching asynchrony in individuals originating from the same brood, which prevents local extinctions if the environment is change abruptly, without the bodies have time to adjust to changes (Seger and Brockman, 1987; Cáceres and Tessier, 2003; King and Masel 2007; Benvenuto et al., 2009). Several groups of microcrustaceans (cladocerans, calanoid copepods and anostracans) present in ephemeral environments use this strategy as a way to ensure success in this type of environment (Saiah and Perrin, 1990; Hairston et al., 1995. Simovich and Hathaway, 1997; Cáceres and Tessier, 2003; Gyllstrom and Hansson, 2004).

The presence of dry nauplii in the material from which the eggs were extracted for the experiment was never reported for this genus. This record shows that nauplii hatch without necessarily going through a period of desiccation, but possibly some other snapshot unidentified environmental factor capable of modifying the dormant stage or avoid it as observed in other species of Branchiopoda (Fryer, 1996). This record suggests that maintaining environmental conditions favourable for longer favours lineages that have sequential development without the need to water stress.

ACKNOWLEDGEMENTS - The Coordenação de Aperfeiçoamento de Pessoal de Nível Superior (CAPES) kindly granted the scholarship to one of us (TPC). We thank Biol. Adalberto Ferreira Guimaráes (CEPLAC-Itabuna), Benthic Ecology Laboratory of the Universidade Estadual de Santa Cruz for logistical support and Dr A. Raw for the critical review of the manuscript and review of the English language. 


\section{REFERENCES}

Arnott, S.E.; Yan N.D.; Magnuson, J.J. and Frost, T.M. 1999. Interannual variability and species turnover of crustacean zooplankton in Shield lakes. Canadian Journal of Fisheries and Aquatic Sciences 56(1): 162172.

Benvenuto, C.; Calabrese, A.; Reed, S. K. and Knott, B. 2009. Multiple hatching events in clam shrimp: Implications for mate guarding behaviour and community ecology. Current Science, 96(1): 130136.

Brendonck, L. and L. De Meester. 2003. Egg banks in freshwater zooplankton: evolutionary and ecological archives in the sediment. Hydrobiologia, 491(1-3): 65-84.

Brendonck, L. 1996. Diapause, quiescence, hatching requirements: what we can learn from large freshwater branchiopods (Crustacea: Branchiopoda: Anostraca, Notostraca, Conchostraca). Hydrobiologia, 320(1): 85-97.

Cáceres, C.E. and Tessier, A.J. 2003. How long to rest: the ecology of optimal dormancy. Ecology, 84(5): 1189-1198.

Demeter, L. 2005. Spatial distribution patterns and conservation status of large branchiopods in the Ciuc Basin. Acta Biologica Debrecina Oecologica Hungarica, 13: 73-83.

Fryer, G. 1996. Diapause, a potent force in the evolution of freshwater crustaceans.Hydrobiologia, 320(1): $1-14$.

Gyllstrom, M. and Hansson, L.A. 2004. Dormancy in freshwater zooplankton: Induction, termination and the importance of benthic-pelagic coupling. Aquatic Sciences, 66 (3): 274-295.

Hairston, N.G.; Dillon, T.A. and DeStasio, B.T. 1990. A field-test for the cues of diapause in a freshwater copepod. Ecology, 71(6): 2218-2223.

Hairston, N.G.; Jr Van Brun, R.A.; Kearns, C.M. and D.R. Engstrom. 1995. Age and survivorship of diapausing eggs in a sediment bank. Ecology, 76(6): 1706-1711.

King, O.D. and Masel, J. 2007. The evolution of bethedging adaptations to rare scenarios. Theoretical Population Biology, 72(4): 560-575.

Lopes, J.P.; Gurgel, H.C.B. and Pontes, C.S. 2011. Comportamento reprodutivo de Dendrocephalus brasiliensis, Pesta 1921 (Crustacea: Anostraca). Ciência Animal Brasileira, 12(4): 617-625.

Marcus, N.H. 1984. Variation in the diapause response of Labidocera aestiva (Copepoda: Calanoida) from different latitudes and its importance in the evolutionary process. Biological Bulletin, 166(1): 127-139.

Marcus, V. and Weeks, S.C. 1997. The effects of pond duration on the life history traits of an ephemeral pond crustacean, Eulimnadia texana. Hydrobiologia, 359(1-3): 213-221.

May, L. 1987. Effect of incubation temperature on the hatching of rotifer resting eggs collected from sediments. Hydrobiologia, 147(1): 335-338.

Melo, A.S. and Froehlich, C.G. 2001. Evaluation of methods for estimating macroinvertebrate species richness using individual stones in tropical streams. Freshwater Biology, 46(6): 711-721.

Pereira, G. and M. Gonzales. 1994. Larval development and population dynamics of Dendrocephalus geayi in temporary ponds from Venezuela. Crustaceana, 66(2): 163-177.

Rabet, N. 2010. Revision of the egg morphology of Eulimnadia (Crustacea, Branchiopoda, Spinicaudata). Zoosystema, 32(3): 373-391.
Rabet, N. and Thiery, A. 1996. The neotropical genus Dendrocephalus (Anostraca: Thamnocephalidae) in Brazil (South America), with a description of two new species. Journal of Natural History, 30: 479-503.

Rogers, D.C.; Weeks, S.C. and Hoeh, W.R. 2010. A new species of Eulimnadia (Crustacea; Branchiopoda; Diplostraca; Spinicaudata) from North America. Zootaxa, 2413: 61-68.

Saiah, H. and Perrin, N. 1990. Autumnal vs Spring hatching in the fairy shrimp Siphonophanes grubii (Dybowski) (Crustacea, Anostraca): Diversified BetHedging Strategy? Functional Ecology, 4(6): 769775.

Sassaman, C. and Weeks. S. C. 1993. The genetic mechanism of sex determination in the Conchostracan shrimp Eulimnadia texana. The American Naturalist,141(2): 314-328.

Schwartz, S.S. and Hebert, P.D.N. 1987. Methods for the activation of the resting eggs of Daphnia. Freshwater Biology, 17(2): 373-379.

Seger, J. and Brockman, H.J. 1987. What is bethedging? Vol. 4, 182-211p. In: P.H. Harvey and L. Partridge (Eds), Oxford Surveys in Evolutionary Biology. Oxford University Press, Oxford.

Simovich, M.A. and Hathaway, S.A. 1997. Diversified bet-hedging as a reproductive strategy of some ephemeral pool anostracans (Branchiopoda).Journal of Crustacean Biology, 17(1): 38-44.

Tejedo, M.; Duarte, H.; Gutiérrez-Pesquera, L.M.; Beltrán, J.F.; Katzenberger, M.; Marangoni, F.; Navas, C.A.; Nicieza, A.G.; Relyea, R.A.; Rezende, E.L.; Richter-Boix, A.; Santos, M.; Simon M. and Solé, M. 2012. El estudio de las tolerancias térmicas para el examen de hipótesis biogeográficas y de la vulnerabilidad de los orga hipótesis biogeográficas y de la vulnerabilidad de los organismos ante el calentamiento global. Ejemplos en anfíbios nismos ante el calentamiento global. Ejemplos en anfíbios. Boletín de la Asociación Herpetológica Española, 23(2): 2-27.

Vandekerkhove, J.; Declerck, S.; Brendonck, L.; CondePorcuna, J.M; Jeppesen, E. and De Meester, L. 2005. Hatching of cladoceran resting eggs: temperature and photoperiod. Freshwater Biology, 50(1): 96-104.

Weeks, S.C.; E.G. Chapman; D.C. Rogers; Senyo, D.M. and Hoeh, W.R. 2009. Evolutionary transitions amongdioecy, androdioecy and hermaphroditism in Limnadiid clam shrimp (Branchiopoda: Spinicaudata). Journal of Evolutionary Biology, 22(9): 1781-1799.

Weeks, S.C.; Marcus, V.; Salisbury, R.L. and Ott, D.W. 2002. Cyst development in the conchostracan shrimp, Eulimnadiatexana (Crustacea: Spinicaudata). Hydrobiologia, 486(3): 289-294.

Weeks, S.C.; Crosser, B.R. and Gray, M.M. 2001. Relative fitness of two hermaphroditic mating types in the androdioecious clam shrimp, Eulimnadia texana. Journal of Evolutionary Biology, 14(1): 83-94.

Weeks, S.C.; Marcus, V. and Alvarez, S. 1997 Notes on the life history of the clam shrimp, Eulimnadia texana. Hydrobiologia, 359(1-3): 191-197.

Weeks, S.C.; Marcus, V. and Crosser, B.R. 1999. Inbreeding depression in a self-compatible, androdioecious crustacean, Eulimnadia texana. Evolution, 53(2): 472-483. 